\title{
Heterogeneous Effects of Urban Sprawl on Economic Development: Empirical Evidence from China
}

\author{
Mingdou Zhang ${ }^{1}$, Yue $\mathrm{Li}^{2}$, Rui Guo ${ }^{1}$ and Yurui Yan ${ }^{2, *}$ \\ 1 School of Economics, Dongbei University of Finance and Economics, Dalian 116025, China; \\ zhangmingdou0537@126.com (M.Z.); 13314558989@163.com (R.G.) \\ 2 School of Economic and Social Development, Dongbei University of Finance and Economics, \\ Dalian 116025, China; liyuew0426@163.com \\ * Correspondence: yanyurui1019@126.com
}

check for updates

Citation: Zhang, M.; Li, Y.; Guo, R.; Yan, Y. Heterogeneous Effects of Urban Sprawl on Economic Development: Empirical Evidence from China. Sustainability 2022, 14 , 1582. https://doi.org/10.3390/ su14031582

Academic Editor: Luca Salvati

Received: 10 December 2021

Accepted: 26 January 2022

Published: 29 January 2022

Publisher's Note: MDPI stays neutral with regard to jurisdictional claims in published maps and institutional affiliations.

Copyright: (C) 2022 by the authors. Licensee MDPI, Basel, Switzerland. This article is an open access article distributed under the terms and conditions of the Creative Commons Attribution (CC BY) license (https:// creativecommons.org/licenses/by/ $4.0 /)$.

\begin{abstract}
Identifying the effects of urban sprawl on urban development is of strategic importance. This study takes 285 prefecture-level and above cities in China as research samples and empirically analyzes the heterogeneous impact of urban sprawl on economic development from 2009 to 2018. Results indicate the threshold effect of urban sprawl on economic development. That is, moderate urban sprawl has a significantly positive influence on economic development, whereas excessive urban sprawl has a significantly negative impact on economic development. The empirical analysis also identifies heterogeneities in the effects of urban sprawl on economic development. Compared with the sprawls of small- and medium-sized cities, those of large cities have a greater negative impact on economic development. Compared with the sprawls of cities dominated by the tertiary industry, those of cities dominated by the secondary industry have a greater negative impact on economic development. Findings of this study have important policy implications for scientific urban expansion, reasonable urban spatial layout, and sustainable urban economic development.
\end{abstract}

Keywords: urban sprawl; economic development; city size; leading industry; urbanization

\section{Introduction}

Urban sprawl and eco-environmental quality are two interconnected issues affecting global urbanization [1]. Urban sprawl occurs when the rate of land urbanization surpasses that of population urbanization, which can result in urban forms characterized by lowdensity, single regional function, and auto-dependence, and has become a significant concern in urban economic development. The urban sprawl phenomenon widely exists in developed countries, as the USA represents. The various types of urban sprawl owing to different forms of urban developments include scattered sprawl of satellite cities spreading around the city, banded sprawl of build-up areas spreading along roads, and circular ripple-like sprawl of disorderly expansion. Accordingly, understanding the economic and social consequences of urban sprawl is vital in achieving high-quality urban economic development and high-level urban spatial planning, particularly in China's new era of domestic and international dual-cycle.

At present, China is in the critical period of transforming the economic development model, optimizing the economic structure, and enhancing the driving force of domestic demand. Hence, maximizing the best use of urban space is significant for achieving efficient urban development. Similar to the cases in developed countries, some new areas in China's urbanization process have been blindly explored for building new towns to expand the extent of cities. Despite the seemingly rapid development of the urban economy, the population and industrial development scales of these areas are substantially behind and insufficient to support the effective functioning of newly developed towns, leading to the emergence of "ghost towns". 
The literature has not reached a consensus on the effects of urban sprawl on economic development. Some studies have found that urban sprawl can promote economic development $[2,3]$. Moreover, with the increase of urban built-up areas in the urban sprawl process, numerous elements and resources are put into production activities, thereby reshaping and upgrading the economic bonus of the clustering effects in the urban sprawl context [4]. By contrast, other studies have concluded that urban sprawl harms local economic development $[5,6]$. High levels of urban sprawl are negatively associated with average labor productivity [7]. In view of this dispute, exploring the heterogeneous impact of urban sprawl on economic development is of theoretical and practical interest. Therefore, we empirically analyze the impact of urban sprawl on economic development and further define the economic development effect of urban sprawl.

The main contributions of this study are briefly summarized as follows. First, after fitting and correcting two kinds of satellite light data, the urban sprawl index is calculated more accurately by using the nighttime light data set of more extended time series, which overcomes the defects of outdated data or short research period when using a single light data. Second, we empirically examine the threshold effect of urban sprawl on economic development and analyze the underlying mechanism. Third, we scrutinize the heterogeneity influence of urban sprawl on economic development from various aspects, including the degree of urban sprawl, urban scale, and urban leading industries, thereby providing empirical references for the effects of urban sprawl under different conditions.

The remainder of this paper is organized as follows. Section 2 briefly reviews the relevant literature. Section 3 presents the theoretical analysis of the underlying mechanism and the research hypotheses. Section 4 introduces the research design. Section 5 provides the empirical results with discussion and robustness test. Lastly, Section 6 concludes this research with the corresponding policy implications.

\section{Literature Review}

The existing literature on urban sprawl can be categorized into four strands: definition, inherent characteristics, driving factors, and social and ecological consequences.

Definition. According to Dutton [8], urban sprawl is a low-density, disordered, and functional land expansion mode along some major traffic roads to the suburbs. Meanwhile, Soule [9] defines urban sprawl as a type of low-density land development, which is dependent on car traffic and occurs at the edge of urban centers. Furthermore, Jaeger and Schwick [10] explain that urban sprawl is a type of urban construction expansion, which builds over beyond the existing built-up areas of cities, and has dispersed spatial configuration and low utilization intensity in the built-up area.

Inherent characteristics. The characteristics of urban sprawl in different countries and regions have both commonness and individuality [11]. These prominent common characteristics include single use development [12], fragmentation [13], shape irregularity [14], low concentration [15], and linear development [16]. Apart from these, Ewing [17] studies the characteristics of urban sprawl in the USA and states that leap-frog land-use patterns, strip commercial development along highways, and extremely low-density single-use developments are the three characteristics of urban sprawl. Zhang and Lou [18] compare the characteristics of urban sprawl in China and the USA. They conclude that the population leading to urban sprawl in the USA comes from the population migration within the city, whereas that in China comes from the population outside the original city; moreover, urban sprawls in the USA and China started at high and low levels of urbanization, respectively. Furthermore, Wang et al. [19] propose that China's urban sprawl originated in low-density urbanization, unlike in the USA and European countries, based on excessive suburbanization and intervention from local governments.

Driving factors. Most existing studies attribute urban sprawl to policy failure and market failure [20]. Viewed from policy failure, Pasha [21] believes that some urban population control policies and land restrictive policies, such as floor area ratio restrictions and building height restrictions, have reduced the density of urban development and 
aggravated the urban sprawl process. Additionally, Gómez-Antonio et al. [22] assume the city government as a rational economic entity. If the benefits of urban sprawl are more significant than the financial costs invested by the government, the planning and development policies will tend to improve the degree of urban sprawl. Viewed from market failure, Brueckner and Helsley [23] find that when open-space amenities are present or when infrastructure is underpriced, the social cost of suburban land development exceeds the private cost faced by builders, thereby leading to inefficient urban expansion. Furthermore, Brueckner [24] uses neoclassical urban economics as basis in proposing that market power is the driving force of urban sprawl, including population growth, increasing household incomes, and transportation improvements.

Social and ecological consequences. These consequences are summarized by RubieraMorollón and Garrido-Yserte [25] as the effects on the intersection among social sustainability, mobility, and sprawl, and the effects on the intersection among climate change, energy efficiency, sprawl, and ecological sustainability. Regarding social consequences, Farber and $\mathrm{Li}$ [26] find that social interaction potential is hampered by decentralization, fragmentation, and long commutes in the largest metropolitan regions in the USA where urban sprawl is a culprit in reducing community-level social interaction. Furthermore, urban sprawl indirectly affects economic mobility and exacerbates income segregation [27,28]. As for ecological consequences, though urban areas occupied small fraction of land as compared to other land use types, their impact on ecosystems is significant [29]. Dupras et al. [30] propose that the dispersed sprawl of low-density urban areas within a territory sharply increases the fragmentation of the territory, thereby isolating the few remaining natural spaces and decreasing their ecological connectivity and biodiversity.

Although many studies have focused on urban sprawl, its effects on urban economic development require profound exploration, and the underlying mechanism and potential heterogeneities should also be examined further. Therefore, we use 285 prefecture-level and above cities in China as research samples, empirically analyze the effects of urban sprawl on economic development, and scrutinize the heterogeneities from various aspects.

\section{Theoretical Analysis and Research Hypothesis}

\subsection{Urban Sprawl and Economic Development}

Different degrees of urban sprawl can have varying effects on economic development. Moderate urban sprawl can improve labor productivity and promote investment and consumption growth, positively influencing economic development [31]. First, the increase of labor force brought by moderate urban sprawl can promote rapid economic growth. Urbanization has triggered the expansion of urban boundaries, resulting in the circulation of farming lands. The rural population living on agricultural production is constantly flooding into the city, shifting from agricultural to non-agricultural production departments. On the one hand, the migrant labor force has supplemented extensive cheap labor for urban construction and development, thereby reducing the labor cost of enterprises. On the other hand, owing to differences in labor's education levels, skills, quality, and work experiences, the labor force is constantly flowing from low-income to high-income industries under the effect of a competitive market, thereby promoting the optimization and upgrade of the urban labor structure and reallocation of production resources, as well as labor productivity. Second, with increased labor income, the demand for social consumption also increases, urging manufacturers to increase input and expand production scale, ultimately promoting urban economic growth. Consumer demand accounts for a large proportion of the total social demand, and can improve social productivity and promote social development. With the increase of unstable factors, such as foreign trade, domestic demand has become the main driving force of China's economic growth. In addition, moderate urban sprawl is generally accompanied by the construction of urban infrastructure, residential housing, and enterprise premises, thereby requiring the input of numerous production factors, bringing extensive investments, and driving the development of related industries. 
By contrast, excessive urban sprawl can harm economic development. First, excessive urban sprawl is likely to cause high economic costs and generally weaken the energy level of the urban economy, thereby leading to a reduction in urban economic development rates [32]. Owing to the expansion of urban boundaries to the suburbs caused by urban sprawl, companies and manufacturers are markedly willing to choose low-cost suburbs, resulting in a mismatch between employment and living space [33]. This unbalanced distribution of population and jobs will cause the lagging effect in allocating labor supply and demand in different regions of cities and high cost of commuting [34]. Second, urban sprawl is not conducive to the development of economic agglomeration. For enterprises located at city boundaries, the low-density expansion of cities will cause rents to increase in the original enterprise cluster areas, and the production and operation costs of enterprises will increase. Some enterprises outside the spatial margins to profitability will be forced to relocate and move to different areas of cities, which is not conducive to enhancing competitiveness and exerting externalities of industrial clusters. In addition, urban sprawl can lead to a decline in economic development of central urban areas. On the one hand, the low-density and loose development of cities leads to the fragmentation of urban structure and function, separating residential communities from gathering centers of employment, shopping, entertainment, and education places, thereby forming small-scale community service centers and residents' living circles. As a result, residents reduce their motivation to consume in the central cities. On the other hand, the convenience of e-commerce is constantly improving, and its door-to-door delivery features are consistent with the needs of residents living in relatively closed communities. Therefore, more consumers purchase required goods and services through the Internet, thereby resulting in consumption decline in central urban areas. Thus, we use the preceding analysis as a basis to propose the following hypothesis:

Hypothesis 1 (H1). Urban sprawl has a threshold effect on economic development.

\subsection{Urban Sprawls and Economic Development of Cities in Different Sizes}

The sprawls of cities with different sizes can have varying impact on economic development. Compared with small- and medium-sized cities, one of the main economic advantages of large cities is that they can gather more and higher-quality production factors, bring cost savings and excess economic benefits through the externality of high concentration of enterprises and residents, and create higher economic density. Although the regional compactness, regional accessibility, and mixed utilization efficiency of lands in large cities are relatively high, the spatial looseness caused by urban sprawls often leads to the general dilution of the agglomeration economy [35]. The commuting distance of residents is longer, with more traffic congestion in large cities than in small- and mediumsized cities, and the sprawls of large cities will increase more commuting and logistics costs. These costs will limit the advantages of resource endowment and the extent to which the spatial agglomeration economy can be realized, limiting the economic activities to a specific spatial scope. In addition, urban sprawl tends to build development zones of different sizes and natures in the periphery of large cities and jump to the surrounding areas, resulting in further sprawl. Owing to the different development foundation and natural conditions of peripheral areas of large cities, the speed and degree of urban sprawl in all directions vary, and cities are prone to disorderly expansion. Among the scattered areas, industrial cooperation and personnel interaction are weak, and the partnership between enterprises cannot be formed, resulting in a loss of urban economic efficiency, which will hinder urban economic development. Thus, we propose the following hypothesis:

Hypothesis 2 (H2). The sprawls of large cities have a greater negative impact on economic development compared with small-and medium-sized cities. 


\subsection{Urban Sprawls and Economic Development of Cities with Different Leading Industries}

The sprawls of cities with different leading industries can have different impact on economic development. The large-scale expansion of urban boundaries takes up extensive farmlands, incorporating part of the suburban agricultural population into cities. Compared with the tertiary industry, the secondary industry, represented by the manufacturing industry, has a limited capacity to absorb the rural migrant labor force. With the upgrading of the industrial structure of manufacturing, improvement of capital structure, and increase of technical contents, the capacity to absorb labor force of the secondary industry is substantially reduced [36]. The sprawls of cities dominated by the secondary industry lead to a relative surplus of migrant labor force initially engaged in agricultural and handicraft productions, thereby resulting in loss of production efficiency. In addition, compared with the tertiary industry, production activities of the secondary industry need more transportation of raw materials and cargo, as well as shared infrastructure, and the production activities of the latter are more sensitive to spatial distance [37]. Along with the expansion of spatial distance in the development of the secondary industry, urban sprawl will reduce the profitability of enterprises through the weakening of personnel exchange, reduction of knowledge spillover, and weakening of the technology diffusion effect, thereby hindering the development of the urban economy. However, the tertiary industry is prevented from becoming considerably sensitive to urban spatial expansion because of its developmental attribute and is naturally less affected by urban sprawl. Thus, we propose the following hypothesis:

Hypothesis 3 (H3). The sprawls of cities dominated by the secondary industry have a greater negative impact on economic development compared with cities dominated by the tertiary industry.

\section{Research Design}

\subsection{Data}

There are two types of nighttime light data, DMSP/OLS and NPP/VIIRS. DMSP provided global nighttime light data from 1992 to 2013 and stopped updating in February 2014. The VIIRS then continue to capture global nighttime light images and provide raw data from 2012 to the present. Owing to the incomparability of the two kinds of data, they cannot be directly used simultaneously, thus limiting the available time-series length of nighttime light data. We select DMSP/OLS data from 2009 to 2013 and NPP/VIIRS data from 2012 to 2018, both of which are from the NOAA National Geophysical Data Center (https:/ / www.ngdc.noaa.gov / eog/download.html, accessed on 15 January 2022), through the correction of these two kinds of data, a longer time-series nighttime light dataset is constructed. First, the preprocessing for DMSP/OLS image data includes mutual correction, continuous correction, and saturation correction [38]. Second, the preprocessing for NPP/VIIRS image data mainly includes synthesizing annual data, resampling, and setting the upper and lower limits of light data [39,40]. Third, based on the 2012-2013 image data collected by DMSP/OLS and NPP/VIIRS, we establish a regression relationship between them and obtain the correlation estimation coefficient, and on this basis, the DN values of VIIRS grid data pixels from 2014 to 2018 are calibrated [41,42]. Finally, we obtain comparable nighttime light image raster data from 2009 to 2018.

To justify the credibility of the empirical results, we eliminate extreme outliers and cities established during 2009 to 2018 from raw samples, leading to 285 prefecture-level and above cities as the final samples.

\subsection{Variable Description}

Dependent variable: economic development level. Prior studies have revealed a stable positive correlation between the average brightness of the light grid and the actual per capita income $[43,44]$. Based on this research result and the calibrated nighttime light data, we take the mean value of light brightness in urban areas as the measure of urban economic development [45]. 
Independent variable: degree of urban sprawl. Based on the existing research [7,37], we investigate urban sprawl from two aspects: urban land sprawl (ULS) and urban population sprawl (UPS).

$$
\begin{gathered}
U L S_{i}=0.5 \times\left(L L_{i}-H L_{i}\right)+0.5 \\
U P S_{i}=0.5 \times\left(L P_{i}-H P_{i}\right)+0.5 \\
S P_{i}=\sqrt{U L S_{i} \times U P S_{i}}
\end{gathered}
$$

where $L L$ (or $H L$ ) denotes the proportion of the land area whose population density is lower (or higher) than the national average value accounts for the total land areas respectively; $L P$ (or HP) denotes the proportion of the population whose population density is lower (or higher) than the national average value accounts for the total population. $S P$ is the urban sprawl index which ranges from 0 to 1 , and the greater value means the higher sprawl degree.

When calculating the sprawl index of the prefecture-level and above cities, it is necessary to determine which places in a city belong to the "urban areas" and master the population of subdivided units inside the city. However, in addition to the census data held once every ten years, demographic data released by city governments at all levels of China are based on registered residents instead of permanent residents and can only be accurately located at county-level administrative units, which not only makes it difficult to reflect the population distribution inside cities, but also has a bias for the calculation of urban population size. In addition, in China's urbanization process, with the continuous expansion of urban scale, some cities have adjusted their administrative divisions to transfer from counties to districts according to development needs. This adjustment results in a large increase of the proportion of built-up areas and population of municipal districts in the particular year, which has nothing to do with the urban sprawl and cannot truly reflect the degree of urban sprawl. Therefore, based on the nighttime light data and LandScan Global Population Database (http:/ / web.ornl.gov/sci/landscan, accessed on 15 January 2022), we first draw on the existing research [37,46] and use ArcGIS to extract the areas (grids) where the light brightness DN values of each city are greater than 10 and the population densities are greater than 1000 person per squared kilometers, so as to delimit the "real" urban areas, as illustrated in Figure 1. Then, combined with the vector data of China's administrative regions, we sum up the grids belonging to urban regions to obtain the average light brightness, urban areas, and resident population of each city in the corresponding year. Finally, we calculate the urban sprawl index by using Formulas (3)-(5). When calculating annual sprawl index, we use the average population density of China's urban areas in 2009 as the standard for delimiting high-density and low-density areas. The reason for choosing a fixed standard rather than a changing one is to make the urban spatial structure of all regions and years more comparable.

Control variables: other factors affecting urban economic development. We use previous studies $[47,48]$ as the basis of control variables, including the urban scale as measured by total urban resident population, industrial structure as measured by proportion of added value of the tertiary industry in GDP, income as measured by per capita wage income, government financial resources as measured by public financial expenditure, economic openness as measured by the proportion of foreign direct investment translated into RMB in GDP, and human capital as measured by the proportion of college students in the total population. The above data are mainly from China Urban Statistical Yearbook and China Urban Construction Statistical Yearbook from 2010 to 2019. The detailed definitions of each variable are shown in Table 1. 


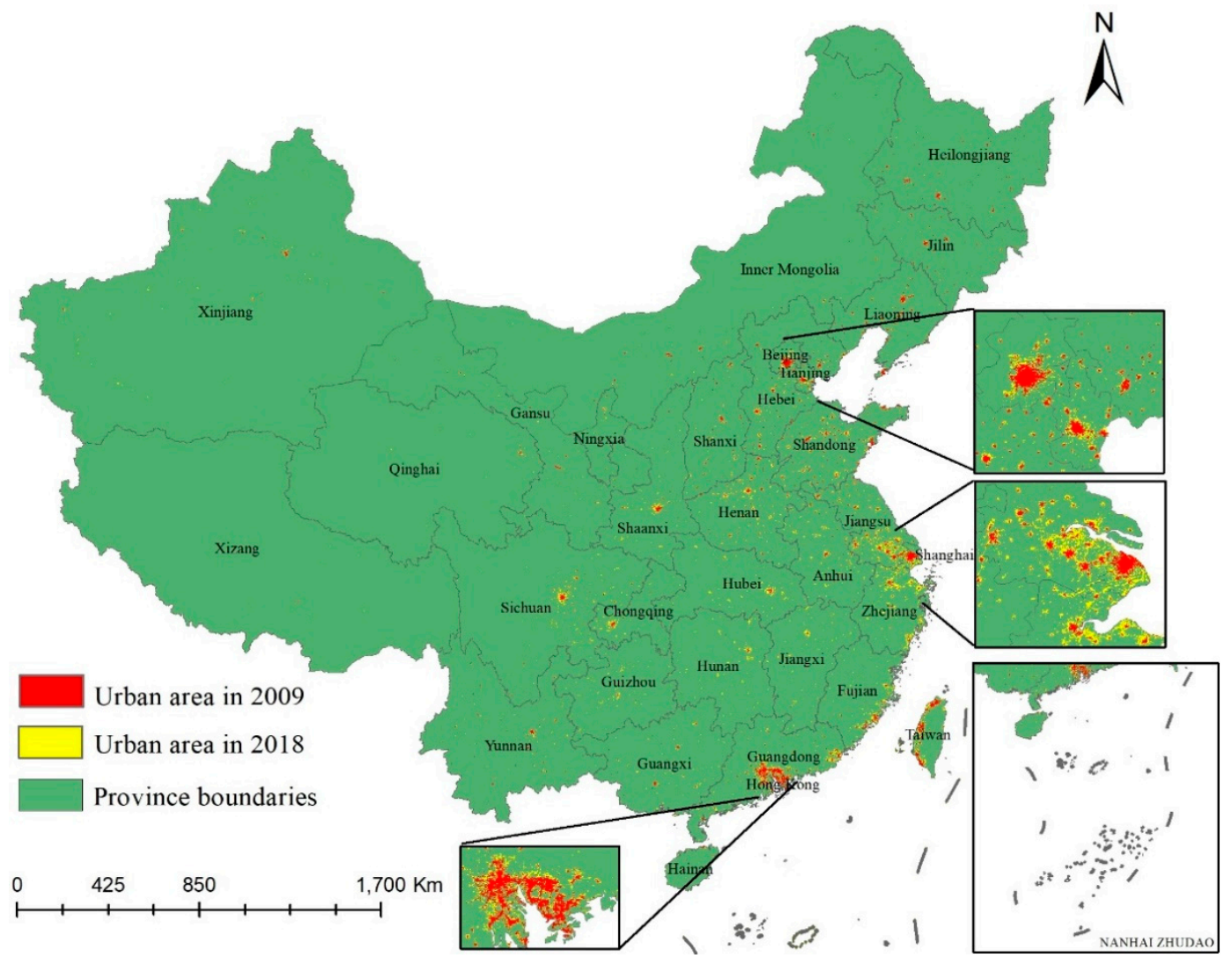

Figure 1. Urban area expansion (2009-2018) across Chinese cities.

Table 1. Variable description.

\begin{tabular}{|c|c|c|c|}
\hline & Variables & Symbols & Variable Definition \\
\hline Dependent variable & Economic development & $\operatorname{lm}$ & $\begin{array}{l}\text { Mean value of nighttime light brightness in } \\
\text { urban areas }\end{array}$ \\
\hline \multirow{5}{*}{$\begin{array}{l}\text { Independent } \\
\text { variable }\end{array}$} & Urban sprawl & $\mathrm{sp}$ & Based on Formulas (1)-(3) \\
\hline & The sprawls of big cities & big & $\begin{array}{l}\text { The sprawl indices of cities with population } \\
\text { greater than } 1 \text { million in urban areas }\end{array}$ \\
\hline & $\begin{array}{l}\text { The sprawls of small and } \\
\text { medium-sized cities }\end{array}$ & sma & $\begin{array}{l}\text { The sprawl indexes of cities with a population of } \\
\text { less than } 1 \text { million in urban areas }\end{array}$ \\
\hline & $\begin{array}{l}\text { The sprawls of cities dominated by } \\
\text { the secondary industry }\end{array}$ & ind & $\begin{array}{l}\text { The sprawl indexes of cities with the highest } \\
\text { proportion of the secondary industry }\end{array}$ \\
\hline & $\begin{array}{l}\text { The sprawls of cities dominated by } \\
\text { the tertiary industry }\end{array}$ & ser & $\begin{array}{l}\text { The sprawl indexes of cities with the highest } \\
\text { proportion of the tertiary industry }\end{array}$ \\
\hline \multirow{6}{*}{ Control variables } & Urban scale & pop & The total urban resident population \\
\hline & Industrial structure & thi & $\begin{array}{l}\text { Proportion of added value of the tertiary } \\
\text { industry in GDP }\end{array}$ \\
\hline & Income & wag & Per capita wage income \\
\hline & Government financial resources & fin & Public financial expenditure \\
\hline & Economic openness & fdi & $\begin{array}{l}\text { The proportion of foreign direct investment } \\
\text { in GDP }\end{array}$ \\
\hline & Human capita & edu & $\begin{array}{c}\text { The proportion of college students in the total } \\
\text { population }\end{array}$ \\
\hline
\end{tabular}




\subsection{Model Specification}

We follow Hansen [49] and construct the following threshold model to verify Hypothesis 1:

$$
\begin{gathered}
l m_{i t}=\beta_{0}+\beta_{1} s p_{i t} \cdot I\left(s p_{i t} \leq \gamma_{1}\right)+\beta_{2} s p_{i t} \cdot I\left(\gamma_{1}<s p_{i t} \leq \gamma_{2}\right)+\cdots+\beta_{n} s p_{i t} \\
\cdot I\left(\gamma_{n}-1<s p_{i t} \leq \gamma_{n}\right)+\beta_{n+1} s p_{i t} \cdot I\left(s p_{i t}>\gamma_{n}\right)+\sum \beta_{k} \text { Controls }_{i t}+\mu_{i}+\sigma_{t}+\varepsilon_{i t}
\end{gathered}
$$

where subscript $i$ represents the city and $t$ represents the year, $\beta_{1}, \beta_{2}, \ldots, \beta_{n+1}$ are regression coefficients; $I(\cdot)$ is the indicator function; $\gamma_{1}, \gamma_{2}, \ldots, \gamma_{n}$ are the thresholds; Controls represents the control variables. Analogously, we build another model to test the other two hypotheses:

$$
l m_{i t}=\beta_{0}+\beta_{1} X_{i t}+\sum \beta_{k} \text { Controls }_{i t}+\mu_{i}+\sigma_{t}+\varepsilon_{i t}
$$

where $X_{i t}$ represents the sprawl index of cities with different urban sizes and leading industries.

We take log-transformation to both the dependent variable and independent variable. In this way, the coefficients of independent variables represent the elasticity between urban sprawl and economic growth. Simultaneously, we also take log-transformation to the urban scale, income and government financial resources in the control variables to reduce estimation bias.

Table 2 shows the descriptive statistics of all variables. After taking the natural logarithm, the maximum value of urban sprawl (sp) is 0.000 , the minimum value is -3.976 , and the mean value is -0.848 . Additionally, the standard deviations of all variables are below 1.000 and the mean values of all control variables have slight difference, thereby implying that the observed values are relatively stable.

Table 2. Descriptive statistics of log-transformed variables.

\begin{tabular}{cccccc}
\hline Variables & Mean & Std. Dev. & Min & Max & Obs \\
\hline $\operatorname{lm}$ & 2.636 & 0.339 & 1.609 & 3.870 & 2850 \\
sp & -0.848 & 0.363 & -3.976 & 0.000 & 2850 \\
pop & 5.876 & 0.701 & 2.970 & 8.133 & 2850 \\
thi & 0.392 & 0.097 & 0.098 & 0.810 & 2850 \\
wag & 10.711 & 0.364 & 8.509 & 11.917 & 2850 \\
fin & 14.673 & 0.787 & 11.544 & 18.246 & 2850 \\
fdi & 0.173 & 0.018 & 0.000 & 0.191 & 2850 \\
edu & 0.180 & 0.024 & 0.000 & 0.131 & 2850 \\
\hline
\end{tabular}

\section{Empirical Analyses}

\subsection{Threshold Effects of Urban Sprawl on Economic Development}

First, we conduct a self-sampling test to identify the potential threshold effects as specified in Model (4). The results are shown in Table 3. The $p$ value of single threshold is less than 0.01 and that of double threshold is greater than 0.05 , which indicate that the single threshold model is preferable. Further calculation identifies the single threshold to be -1.693 , as shown in Table 4 . We use the results of the threshold test as bases to specify Model (4) as the single threshold regression model as follows:

$$
\operatorname{lm}_{i t}=\beta_{0}+\beta_{1} D_{1}+\beta_{2} s p_{i t}+\beta_{3} s p_{i t} \cdot D_{1}+\sum \beta_{k} \text { Controls }_{i t}+\varepsilon_{i t}
$$

where $D_{1}$ is a dummy variable: $s p_{i t} \leq-1.693, D_{1}=0$; otherwise, $D_{1}=1$. The indicative function $I(\cdot)$ can be simply expressed as $D_{1}=\mathrm{I}\left(s p_{i t}>-1.693\right)$.

Table 5 shows the results of the single threshold regression model. When the sprawl index is no more than the single threshold (i.e., -1.693), urban sprawl has a significantly positive effect on economic development. Moreover, when the sprawl index is greater than the single threshold, the effect of urban sprawl becomes significantly negative. Thus, Hypothesis 1 is verified. 
Table 3. Self-sampling test of the threshold effect.

\begin{tabular}{ccccccc}
\hline \multirow{2}{*}{ Model } & \multirow{2}{*}{ F Statistics } & $p$-Value & BS Times & \multicolumn{3}{c}{ Critical Values } \\
\cline { 5 - 7 } & & & & $\mathbf{1 \%}$ & $\mathbf{5 \%}$ & $\mathbf{1 0 \%}$ \\
\hline Single threshold & $44.61^{* * *}$ & 0.003 & 300 & 28.989 & 21.307 & 18.309 \\
Double threshold & $22.18^{*}$ & 0.053 & 300 & 25.305 & 19.990 & 16.606 \\
\hline Notes: ${ }^{* * *} p<0.01,^{*} p<0.1$. & & & & & &
\end{tabular}

Table 4. Statistical inferences of single threshold.

\begin{tabular}{|c|c|c|}
\hline \multicolumn{2}{|c|}{ Estimated Threshold } & 95\% Confidence Interval \\
\hline$\gamma_{1}$ & -1.693 & {$[-1.740,-1.596]$} \\
\hline
\end{tabular}

Table 5. Regression results of the single threshold model.

\begin{tabular}{|c|c|}
\hline Variables & (1) \\
\hline $\begin{array}{c}\text { sp_1 } \\
(\mathrm{sp} \leq-1.693)\end{array}$ & $\begin{array}{c}0.073^{* * *} \\
(7.13)\end{array}$ \\
\hline $\begin{array}{c}\text { sp_2 } \\
(-1.693<\mathrm{sp})\end{array}$ & $\begin{array}{l}-0.318^{* * *} \\
(-13.90)\end{array}$ \\
\hline pop & $\begin{array}{c}0.176 \text { ** } \\
(2.37)\end{array}$ \\
\hline thi & $\begin{array}{c}-0.567^{* * *} \\
(-6.01)\end{array}$ \\
\hline wag & $\begin{array}{c}0.152^{* * *} \\
(5.12)\end{array}$ \\
\hline fin & $\begin{array}{c}-0.093^{* * *} \\
(4.10)\end{array}$ \\
\hline fdi & $\begin{array}{l}0.092 \\
(0.26)\end{array}$ \\
\hline edu & $\begin{array}{l}-0.697 \\
(-0.83)\end{array}$ \\
\hline cons & $\begin{array}{c}-1.356^{* * *} \\
(-3.29)\end{array}$ \\
\hline R-squared & 0.267 \\
\hline $\mathrm{N}$ & 2850 \\
\hline
\end{tabular}

Notes: $t$ statistics in parentheses; ${ }^{* * *} p<0.01,{ }^{* *} p<0.05$.

When smart growth mode according to scientific urban spatial planning is implemented in cities, it can efficiently gather economic factors and maximize the utility of limited economic resources. However, excessive urban sprawl promotes the scattered distribution of population activities and factors; separation of residential communities from employment, shopping, entertainment, and education sites; and reduction of regional connectivity, thereby hindering the development of the urban economy. Specific to China's reality, some large cities are actively exploring effective urban spatial growth strategies. Since 2014, 14 cities, including Beijing, Shanghai, Guangzhou, and Shenzhen, have been delimited urban development boundaries. This measure has effectively curbed the urban sprawl trend, improved urban land use efficiency, optimized urban spatial structure, and achieved excellent economic and ecological benefits. However, numerous cities have experienced excessive sprawl. The GDP-oriented development approach has spawned some cities in China to invest huge funds in developing and constructing new towns. However, owing to such factors as small population size and long distance from central cities to new towns, investment attraction is weak and development speed is slow, which cannot form a 
new urban economic growth point. Lastly, new city construction evolves into a large-scale real estate development movement, and high housing vacancy rates cause the occurrence of the "empty-city stratagem". The imbalance of economic input-output ratio brought about by new town construction has caused the waste of land and capital and also aggravated the severity of urban sprawl. Moreover, some local governments cannot implement the secondary reconstruction and development of main urban areas due to the high debt of supporting facilities for the construction of new towns. This situation has overdrawn the development potential of cities and resulted in insurmountable difficulties for the urban development.

\subsection{Heterogeneous Effects of Sprawling Cities in Different Sizes}

To examine the heterogeneous effects of sprawls of cities in different sizes, we fit Model (5) with the sprawls of large cities and small- and medium-sized cities being the main explanatory variables. The empirical results are shown in Table 6. The sprawls of large cities have a greater negative impact on economic development compared with smalland medium-sized cities. Hence, Hypothesis 3 is verified. The sprawls of large cities make it costly to establish production links and personnel technical exchanges between the development zones in different directions of cities. In addition, production and business activities are separated from one another. Thus, the loss of agglomeration economic externality is greater than that of small- and medium-sized cities.

Table 6. Regression results of the impact of the sprawls of cities in different sizes.

\begin{tabular}{|c|c|c|}
\hline Variables & (1) & (2) \\
\hline big & $\begin{array}{c}-0.505^{* * *} \\
(-4.04)\end{array}$ & \\
\hline sma & & $\begin{array}{c}-0.200 * * * \\
(-4.99)\end{array}$ \\
\hline Controls & $\mathrm{Y}$ & $\mathrm{Y}$ \\
\hline City FE & $Y$ & $Y$ \\
\hline Year FE & Y & $\mathrm{Y}$ \\
\hline R-squared & 0.385 & 0.319 \\
\hline $\mathrm{N}$ & 740 & 2110 \\
\hline
\end{tabular}

Notes: $t$ statistics in parentheses; ${ }^{* * *} p<0.01$.

In China's urbanization process, the population continues to gather in large cities, and the built-up areas of these cities are expanding. However, in the process of expansion, the growth rate of built-up areas exceeds the growth rate of the population. Young people who cannot afford to buy or rent houses in urban core areas face increasing commuting distances, and the road connecting city centers and suburbs is heavily congested. In addition, high-grade residential areas with low plot ratio in better environment of suburban areas aggravate the sprawl of large cities. This situation results in a wide disparity in population density between the central and suburban areas, and the urban spatial layout is deformed.

\subsection{Heterogeneous Effects of Sprawling Cities with Different Leading Industries}

To examine the heterogeneous effects of sprawls of cities with different leading industries, we fit Model (5) with the sprawls of cities dominated by the tertiary and secondary industries. The regression results are shown in Table 7. Compared with cities dominated by the tertiary industry, the sprawls of cities dominated by the secondary industry have a greater negative impact on economic development. Hence, Hypothesis 4 is verified. The increase of logistics cost and rent and decrease of infrastructure sharing efficiency caused by cities dominated by the secondary industry substantially reduce the production 
efficiency and economic benefits of enterprises. Moreover, the loss of industrial competitive advantage is more serious than that of tertiary industry-dominated cities.

Table 7. Regression results of the impact of the sprawls of cities with different leading industries.

\begin{tabular}{ccc}
\hline Variables & (1) & (2) \\
\hline ind & $\begin{array}{c}-0.286^{* * *} \\
(-4.99)\end{array}$ \\
\hline ser & & $-0.206^{* * *}$ \\
& & $(-3.87)$ \\
\hline Controls & $\mathrm{Y}$ & $\mathrm{Y}$ \\
\hline City FE & $\mathrm{Y}$ & $\mathrm{Y}$ \\
\hline Year FE & $\mathrm{Y}$ & $\mathrm{Y}$ \\
\hline R-squared & 0.393 & 0.289 \\
\hline $\mathrm{N}$ & 1250 & 1600 \\
\hline Notes: tstatistics in parenthes*** $p<0.01$ & &
\end{tabular}

Notes: $t$ statistics in parentheses; ${ }^{* * *} p<0.01$

With the acceleration of the transformation and upgrade of China's industrial structure, the majority of the cities dominated by the secondary industry are traditional industrial or underdeveloped cities at the middle and low end of the industrial chain. Under the background of resolution of excess capacity and strict control of polluting enterprises countrywide, numerous industrial cities dominated by the secondary industry have insufficient capacity to absorb the population owing to serious environmental pollution and limited employment opportunities. In addition, the development of private economy and modern service industry is relatively lagging. Consequently, urban centers lack popularity and vitality. The sprawls of these cities accelerate the decline of the central urban area and generally reduce resilience and competitiveness of the urban economy.

\subsection{Robustness Test}

To test the robustness of the threshold model, we use the growth rate of per capita GDP to measure urban economic development and adopt an alternative approach for constructing the urban sprawl index [50] as follows:

$$
S P_{\rho}=1-\frac{U P_{t} / B A_{t}}{U P_{0} / B A_{0}}=1-\frac{\rho_{t}}{\rho_{0}}
$$

where $B A_{t}$ and $U P_{t}$ represent the proportion of the built-up area and population of the municipal district, respectively, in the current period; $B A_{0}$ and $U P_{0}$ represent the proportion of the built-up area and population of the municipal district, respectively, in the base period; $\rho_{t}$ is the urban population density of the current period; and $\rho_{0}$ is the urban population density of the base period.

After eliminating the cities affected by administrative division adjustment and abnormal data, the remaining 207 cities at prefecture-level and above are used as samples for robustness test.

Table 8 shows the results of the threshold effect test based on the new variables. Evidently, the threshold model with two thresholds remains preferable. Table 9 shows that the two thresholds are 0.036 and 0.079 , respectively. According to the results of the threshold test, Model (4) is refitted as the double threshold regression model based on the new setting, as follows:

$$
l m_{i t}=\beta_{0}+\beta_{1} D_{1}+\beta_{2} D_{2}+\beta_{3} s p_{i t}+\beta_{4} s p_{i t} \cdot D_{1}+\beta_{5} s p_{i t} \cdot D_{2}+\sum \beta_{k} \text { Controls }_{i t}+\varepsilon_{i t}
$$

where $D_{1}$ and $D_{2}$ are dummy variables: when $s p_{i t} \leq 0.036, D_{1}=D_{2}=0$; when $0.036<s p_{i t}$ $\leq 0.079, D_{1}=1, D_{2}=0$; when $s p_{i t}>0.079, D_{1}=0, D_{2}=1$. 
Table 8. Self-sampling test of the threshold effect based on the new variables.

\begin{tabular}{ccccccc}
\hline \multirow{2}{*}{ Model } & \multirow{2}{*}{ F Statistics } & $\boldsymbol{p}$-Value & \multirow{2}{*}{ BS Times } & \multicolumn{3}{c}{ Critical Values } \\
\cline { 5 - 7 } & & & & $\mathbf{1 \%}$ & $\mathbf{5 \%}$ & $\mathbf{1 0 \%}$ \\
\hline Single threshold & $14.825^{* *}$ & 0.027 & 300 & 19.702 & 8.265 & 3.181 \\
Double threshold & $8.148^{* *}$ & 0.023 & 300 & 10.705 & 6.204 & 4.084 \\
Triple threshold & $3.932^{*}$ & 0.060 & 300 & 9.805 & 5.404 & 2.535 \\
\hline
\end{tabular}

Notes: ${ }^{* *} p<0.05,{ }^{*} p<0.1$.

Table 9. Statistical inferences of the thresholds based on the new variables.

\begin{tabular}{cccc}
\hline \multicolumn{3}{c}{ Estimated Threshold } & 95\% Confidence Interval \\
\hline$\gamma_{1}$ & 0.036 & {$[-0.170,0.600]$} \\
\hline$\gamma_{2}$ & 0.079 & {$[-0.244,0.600]$} \\
\hline
\end{tabular}

The results shown in Table 10 are consistent with the main results. First, when the sprawl index is no more than the first threshold (i.e., 0.036), urban sprawl has a significantly positive effect on economic development. Second, when the sprawl index is above 0.036 , urban sprawl has a significantly negative impact on economic development. Lastly, the higher the degree of sprawl, the greater the negative effect of urban sprawl on economic development. Although the threshold number of robustness test is more than that of primary regression, the results still verify Hypothesis 1.

Table 10. Results of the robustness test.

\begin{tabular}{cc}
\hline Variables & $\mathbf{( 1 )}$ \\
\hline $\mathrm{sp} \_1$ & $0.133^{*}$ \\
$(\mathrm{sp} \leq 0.036)$ & $(1.94)$ \\
\hline $\mathrm{sp} \_2$ & $-0.0226^{* *}$ \\
$(0.036<\mathrm{sp} \leq 0.079)$ & $(-2.21)$ \\
\hline $\mathrm{sp} \_3$ & $-0.156^{* * *}$ \\
$(\mathrm{sp}>0.079)$ & $(-4.95)$ \\
\hline Controls & $\mathrm{Y}$ \\
\hline R-squared & 0.215 \\
\hline $\mathrm{N}$ & 2070
\end{tabular}

Notes: $t$ statistics in parentheses; ${ }^{* * *} p<0.01,{ }^{* *} p<0.05,{ }^{*} p<0.1$.

\section{Conclusions}

This study uses 285 prefecture-level and above cities in China as the research samples and empirically analyzes the heterogeneous effects of urban sprawl on economic development from 2009 to 2018. The main conclusions are as follows. First, urban sprawl has a threshold effect on economic development. When urban sprawl is moderate, it has a significantly positive influence on economic development. However, when urban sprawl is excessive, it has a significantly negative impact on economic development. The higher the degree of urban sprawl, the greater the negative impact on economic development. Second, the sprawls of cities in different sizes have varying impact on economic development. The sprawls of large cities have a greater negative impact on economic development compared to small- and medium-sized cities. Third, the sprawls of cities with different leading industries have varying effects on economic development. The sprawls of cities dominated by the secondary industry have a greater negative impact on economic development compared with cities dominated by the tertiary industry.

This study proposes the following policy implications by analyzing the impact of urban sprawl and its heterogeneity on economic development, combined with the specific reality of urban development in China. First, overdone is worse than undone. Moderate 
urban sprawls can effectively improve the utilization efficiency of urban land resources and positively affect urban economic development. However, excessive urban sprawls will hinder urban economic development. This result highlights the importance of land planning based on sustainable development, which is the method to achieve high-quality urban development with improved efficiency under the condition that urban available land area remains invariable. Furthermore, the transformation of urban growth to the direction of stuffed exploitation and intensive development should be promoted, and the utilization of the internal potential of constructed urban areas is necessary. Second, bigger may not be better. The sprawls of large cities will generally increase the cost of economic operation and lose the economic benefits of agglomeration compared with smalland medium-sized cities. Therefore, large cities should implement smart growth strategy and control the development boundary of cities more strictly. Adopting and enforcing smart growth policies is key not only in creating a more compact city but may also help to promote sustainable urban development. Third, the optimization of industrial structure is important. The development of the tertiary industry has minimal effects on the demand for urban land and has inherent advantages in mitigating the negative impact of excessive sprawl. Therefore, cities should adjust their industrial structures according to the dynamic characteristics of industrial agglomeration while maintaining good coordination between the development of the secondary and tertiary industries.

Author Contributions: Data curation, Y.L. and R.G.; writing-original draft preparation, M.Z. and Y.Y.; writing-review and editing, M.Z. and Y.Y.; project administration, M.Z.; funding acquisition, M.Z. All authors have read and agreed to the published version of the manuscript.

Funding: This research was funded by the National Natural Science Foundation of China (71804021).

Institutional Review Board Statement: Not applicable.

Informed Consent Statement: Not applicable.

Data Availability Statement: Please contact the corresponding author. The data are not publicly available due to conditional requests from the source.

Acknowledgments: The authors would like to thank the editors and anonymous reviewers for their constructive comments and suggestions.

Conflicts of Interest: The authors declare no conflict of interest.

\section{References}

1. Wigginton, N.S.; Fahrenkamp-Uppenbrink, J.; Wible, B.; Malakoff, D. Cities are the future. Science 2016, 352, 904-905. [CrossRef]

2. Ma, L.J.C. Urban administrative restructuring, changing scale relations and local economic development in China. Polit. Geogr. 2005, 24, 477-497. [CrossRef]

3. Zhang, C.; Miao, C.; Zhang, W.; Chen, X. Spatiotemporal patterns of urban sprawl and its relationship with economic development in China during 1990-2010. Habitat Int. 2018, 79, 51-60. [CrossRef]

4. Chen, D.; Lu, X.; Liu, X.; Wang, X. Measurement of the eco-environmental effects of urban sprawl: Theoretical mechanism and spatiotemporal differentiation. Ecol. Indic. 2019, 105, 6-15. [CrossRef]

5. Galster, G.; Hanson, R.; Ratcliffe, M.R.; Wolman, H.; Coleman, S.; Freihage, J. Wrestling sprawl to the ground: Defining and measuring an elusive concept. Hous. Policy Debate 2001, 12, 681-717. [CrossRef]

6. Lityński, P.; Hołuj, A. Macroeconomic perspective on urban sprawl: A multidimensional approach in Poland. Land 2021, 10, 116. [CrossRef]

7. Fallah, B.N.; Partridge, M.D.; Olfert, M.R. Urban sprawl and productivity: Evidence from US metropolitan areas. Pap. Reg. Sci. 2011, 90, 451-472. [CrossRef]

8. Dutton, J.A. New American Urbanism: Reforming the Suburban Metropolis; London Distributed Elsewhere by Thames \& Hudson: London, UK, 2000.

9. Soule, D.C. Urban Sprawl: A Comprehensive Reference Guide; Greenwood Publishing Group: Santa Barbara, CA, USA, 2006.

10. Jaeger, J.A.; Schwick, C. Improving the measurement of urban sprawl: Weighted urban proliferation (WUP) and its application to Switzerland. Ecol. Indic. 2014, 38, 294-308. [CrossRef]

11. Catalán, B.; Saurí, D.; Serra, P. Urban sprawl in the Mediterranean? Patterns of growth and change in the Barcelona Metropolitan Region 1993-2000. Landsc. Urban Plan. 2008, 85, 174-184. [CrossRef]

12. Wei, Y.D.; Ewing, R. Urban expansion, sprawl and inequality. Landsc. Urban Plan. 2018, 177, 259-265. [CrossRef] 
13. Liu, L.; Meng, L. Patterns of urban sprawl from a global perspective. J. Urban Plan. Dev. 2020, 146, 04020004. [CrossRef]

14. Keita, M.A.; Ruan, R.; An, R. Spatiotemporal change of urban sprawl patterns in Bamako District in Mali based on time series analysis. Urban Sci. 2021, 5, 4. [CrossRef]

15. Tsai, Y.H. Quantifying urban form: Compactness versus "sprawl". Urban Stud. 2005, 42, 141-161. [CrossRef]

16. Guite, L.T.S. Assessment of urban sprawl in Bathinda city, India. J. Urban Manag. 2019, 8, 195-205. [CrossRef]

17. Ewing, R. Counterpoint: Is Los Angeles-style sprawl desirable? J. Am. Plan. Assoc. 1997, 63, 107-126. [CrossRef]

18. Zhang, J.; Lou, C. New ideas on Chinese urban sprawl governance by contrasting Chinese and American urban sprawl. Resour. Sci. 2014, 36, 2131-2139.

19. Wang, X.; Shi, R.; Zhou, Y. Dynamics of urban sprawl and sustainable development in China. Ecol. Res. 2006, 21, 221-237. [CrossRef]

20. Fan, J.; Zhou, L. Three-dimensional intergovernmental competition and urban sprawl: Evidence from Chinese prefectural-level cities. Land Use Policy 2019, 87, 104035. [CrossRef]

21. Pasha, H.A. Suburban minimum lot zoning and spatial equilibrium. J. Urban. Econ. 1996, 23, 1-12. [CrossRef]

22. Gómez-Antonio, M.; Hortas-Rico, M.; Li, L. The causes of urban sprawl in Spanish urban areas: A spatial approach. Spat. Econ. Anal. 2006, 11, 1742-1772. [CrossRef]

23. Brueckner, J.K.; Helsley, R.W. Sprawl and blight. J. Urban. Econ. 2011, 38, 205-213. [CrossRef]

24. Brueckner, J.K. Urban sprawl: Diagnosis and remedies. Int. Reg. Sci. Rev. 2000, 23, 160-171. [CrossRef]

25. Rubiera-Morollón, F.; Garrido-Yserte, R. Recent literature about urban sprawl: A renewed relevance of the phenomenon from the perspective of environmental sustainability. Sustainability 2020, 12, 6551. [CrossRef]

26. Farber, S.; Li, X. Urban sprawl and social international interaction potential: An empirical analysis of large metropolitan regions in the United States. J. Transp. Geogr. 2013, 31, 267-277. [CrossRef]

27. Reardon, S.F.; Bischoff, K. Income inequality and income segregation. Am. J. Sociol. 2011, 116, 1092-1153. [CrossRef] [PubMed]

28. Ewing, R.; Hamidi, S.; Grace, J.B.; Wei, Y.D. Does urban sprawl hold down upward mobility? Landsc. Urban Plan. 2016, 148, 80-88. [CrossRef]

29. Getu, K.; Bhat, H.G. Analysis of spatio-temporal dynamics of urban sprawl and growth pattern using geospatial technologies and landscape metrics in Bahir Dar, Northwest Ethiopia. Land Use Policy 2021, 109, 105676. [CrossRef]

30. Dupras, J.; Marull, J.; Parcerisas, L.; Coll, F.; Gonzalez, A.; Girard, M.; Tello, E. The impacts of urban sprawl on ecological connectivity in the Montreal Metropolitan Region. Environ. Sci. Policy 2016, 58, 61-73. [CrossRef]

31. Huang, Z.; Wei, Y.D.; He, C.; Li, H. Urban land expansion under economic transition in China: A multi-level modeling analysis. Habitat Int. 2015, 47, 69-82. [CrossRef]

32. Vermeiren, K.; Crols, T.; Uljee, I.; Nocker, L.D.; Beckx, C.; Pisman, A.; Broekx, S.; Poelmans, L. Modelling urban sprawl and assessing its costs in the planning process: A case study in Flanders, Belgium. Land Use Policy 2021, 113, 105902. [CrossRef]

33. Nilles, J.M. Telecommuting and urban sprawl: Mitigator or inciter? Transportation 1991, 18, 411-432. [CrossRef]

34. Smith, R.M.; Blizard, Z.D. A census tract level analysis of urban sprawl's effects on economic mobility in the United States. Cities 2021, 115, 103232. [CrossRef]

35. Chen, X.; Qin, M.; Liu, X. Urban sprawl, dynamic externality and firms' export: An empirical research based on China's manufacturing enterprise data. Financ. Trade Econ. 2018, 39, 145-160.

36. Tregenna, F. Characterising deindustrialisation: An analysis of changes in manufacturing employment and output internationally. Camb. J. Econ. 2009, 33, 433-466. [CrossRef]

37. Qin, M.; Liu, X.; Li, S. The impact of urban sprawl on regional economic growth: Empirical researches based on DMSP night-time light data. China Econ. Q. 2019, 18, 527-550.

38. Cao, Z.; Wu, Z.; Kuang, Y.; Huang, N. Correction of DMSP/OLS night-time light images and its application in China. Int. J. Geo-Inf. Sci. 2015, 17, 1092-1102.

39. Lv, Q.; Liu, H.; Wang, J.; Liu, H.; Shang, Y. Multiscale analysis on spatiotemporal dynamics of energy consumption $\mathrm{CO}_{2}$ emissions in China: Utilizing the integrated of DMSP-OLS and NPP-VIIRS nighttime light datasets. Sci. Total Environ. 2020, 703, 134394. [CrossRef]

40. Zheng, Q.; Weng, Q.; Wang, K. Developing a new cross-sensor calibration model for DMSP-OLS and Suomi-NPP VIIRS night-light imageries. ISPRS J. Photogramm. Remote Sens. 2019, 153, 36-47. [CrossRef]

41. Liang, L.; Bian, J.; Li, A.; Feng, W.; Lei, G.; Zhang, Z.; Zuo, J. Consistent intercalibration of nighttime light data between DMSP/OLS and NPP/VIIRS in the China-Pakistan Economic Corridor. J. Remote Sens. 2020, 24, 149-160.

42. Elvidge, C.D.; Zhizhin, M.; Ghosh, T.; Hsu, F.C.; Taneja, J. Annual time series of global VIIRS nighttime lights derived from monthly averages: 2012 to 2019. Remote Sens. 2021, 13, 922. [CrossRef]

43. Xu, K.; Chen, F.; Liu, X. The truth of China economic growth: Evidence from global night-time light data. Econ. Res. J. 2015, 61, 17-29.

44. Fan, Z.; Peng, F.; Liu, C. Political connections and economic growth: Evidence from the DMSP/OLS satellite data. Econ. Res. J. 2016, 62, 114-126.

45. Podobnik, B.; Shao, J.; Njavro, D.; Ivanov, P.C.; Stanley, H.E. Influence of corruption on economic growth rate and foreign investment. Eur. Phys. J. B 2008, 63, 547-550. [CrossRef] 
46. Yi, K.; Tani, H.; Li, Q.; Zhang, J.; Guo, M.; Bao, Y.; Wang, X.; Li, J. Mapping and evaluating the urbanization process in Northeast China using DMSP/OLS night time light data. Sensors 2014, 14, 3207-3226. [CrossRef]

47. Hussain, A.; Oad, A.; Ahmad, M.; Irfan, M.; Saqib, F. Do financial development and economic openness matter for economic progress in an emerging country? Seeking a sustainable development path. Sustainability 2021, 14, 237. [CrossRef]

48. Feng, Y.; Wang, X.; Du, W.; Liu, J.; Li, Y. Spatiotemporal characteristics and driving forces of urban sprawl in China during 2003-2017. J. Clean. Prod. 2019, 241, 118061. [CrossRef]

49. Hansen, B.E. Sample splitting and threshold estimation. Econometrica 2000, 68, 575-603. [CrossRef]

50. Wang, J.; Zhao, Y.; Li, Y.; Cai, S. The impact of urban sprawl on private car development: An analysis based on panel data of 269 cities in China. Urban Probl. 2019, 38, 93-103. 